Research Article

\title{
Demonstration of Millimeter Wave 5G Setup Employing High-Gain Vivaldi Array
}

\author{
Waleed Tariq Sethi $\mathbb{D}^{1}$ Muhammad Ahmed Ashraf $\mathbb{D}^{1},{ }^{1}$ Amr Ragheb, ${ }^{1}$ Amr Alasaad $\mathbb{D},{ }^{2}$ \\ and Saleh A. Alshebeili ${ }^{1}$ \\ ${ }^{1}$ KACST Technology Innovation Center in radio frequency and photonics for the e-Society (RFTONICS), College of Engineering, \\ King Saud University, Riyadh 11421, Saudi Arabia \\ ${ }^{2}$ National Center for Electronics and Photonics Technology, King Abdulaziz City for Science and Technology in Riyadh, \\ Riyadh, Saudi Arabia
}

Correspondence should be addressed to Muhammad Ahmed Ashraf; mashraf@ksu.edu.sa

Received 3 December 2017; Accepted 1 March 2018; Published 23 April 2018

Academic Editor: Muhammad Ramlee Kamarudin

Copyright (c) 2018 Waleed Tariq Sethi et al. This is an open access article distributed under the Creative Commons Attribution License, which permits unrestricted use, distribution, and reproduction in any medium, provided the original work is properly cited.

\begin{abstract}
We present a $4 \times 4$ slot-coupled Vivaldi antenna (SCVA) array unit cell, which offers wide bandwidth and high gain $(\sim 23 \mathrm{dBi})$ at the millimeter wave $(\mathrm{mmW})$ frequencies of $28 \mathrm{GHz}$ and $38 \mathrm{GHz}$. A single SCVA element is first presented, which has a bandwidth of $25-40 \mathrm{GHz}$ with an average gain of $\sim 13 \mathrm{dBi}$ at the frequencies of interest. This antenna element is then used to design a $1 \times 4$ linear SCVA array matched to a $50 \Omega$ impedance via a modified Wilkinson power divider (WPD). Next, the $1 \times 4$ linear array is used to construct a $4 \times 4$ antenna array unit cell. The proposed $4 \times 4$ antenna array unit cell is fabricated, and the characteristics of its elements (i.e., the single SCVA, $1 \times 4$ linear array, and WPD) are thoroughly investigated. Further, the $4 \times 4$ array is tested for signal reception of various digital modulation formats at lab environment using high-speed digital signal oscilloscope. In particular, a $2.5 \mathrm{Gbps}$ data rate is successfully transmitted achieving receiver sensitivity of $-50 \mathrm{dBm}$ at $2 \times 10^{-3}$ bit error rate (BER) for 32 quadrature amplitude modulation (QAM) with a system baud rate of $500 \mathrm{MHz}$. The wide bandwidth and high gain along with the excellent performance of the proposed $4 \times 4$ antenna array unit cell makes it an excellent candidate for future $5 \mathrm{G}$ wireless communication applications.
\end{abstract}

\section{Introduction}

Rapid development of wireless networking techniques in the last decade have introduced a bundle of wireless services that are being utilized by various smart devices. These devices consume massive bandwidth and are still hungry for more, which in turn increase the data traffic on the wireless networks [1]. In order to satisfy the ever-growing demands of consumers and wireless market, the millimeter wave $(\mathrm{mmW})$ band, with its huge bandwidth compared to that of the currently utilized bands for wireless communications, seems to provide a promising solution. The $\mathrm{mmW}$ band has attracted a lot of attention over the last years from both the scientific research community and industry alike, as it is acknowledged for being a key technology in the development and implementation of the fifth generation (5G) mobile communication systems [2-4]. The standardization of 5G communication frequency bands and networking protocols, along with the development of commercial hardware, is underway and expected to be ready by early 2020 [5].

One key enabling technique in $5 \mathrm{G}$ communication systems is the use of mmW antenna arrays for signal transmission and reception. The design of antenna arrays of wideband and high-gain characteristics in the $\mathrm{mmW}$ band is a challenging task. Few attempts have been reported in the literature considering the design of $\mathrm{mmW}$ antenna arrays at $28 \mathrm{GHz}$ and/or $38 \mathrm{GHz}$. In [6], a 5G-phased array mobile communication is considered, where the array consists of ten-slot loop antennas. The antenna array is designed using FR-4 substrate with reported gain around $13 \mathrm{dBi}$, covering the band from $27 \mathrm{GHz}$ to $29 \mathrm{GHz}$. Because of the utilized substrate, this design intrinsically exhibits high losses, which are 
TABLE 1: Characteristic comparison of various Vivaldi antenna designs.

\begin{tabular}{|c|c|c|c|c|c|c|c|c|}
\hline \multicolumn{5}{|c|}{ Single element } & \multicolumn{4}{|c|}{ Arrays } \\
\hline Ref. & Frequency & $\begin{array}{c}\text { Bandwidth } \\
\text { (GHz) }\end{array}$ & $\begin{array}{l}\text { Gain } \\
(\mathrm{dBi})\end{array}$ & $\begin{array}{l}\text { Dimensions } \\
(\mathrm{mm})\end{array}$ & $\begin{array}{l}\text { Bandwidth } \\
\text { (GHz) }\end{array}$ & $\begin{array}{l}\text { Gain } \\
(\mathrm{dBi})\end{array}$ & $\begin{array}{l}\text { Number of } \\
\text { elements }\end{array}$ & $\begin{array}{l}\text { Dimensions } \\
(\mathrm{mm})\end{array}$ \\
\hline [17] & $32 \mathrm{GHz}$ & $24.5-40$ & 7 & $14 \times 8 \times 0.508$ & $28-38$ & 15 & $1 \times 8$ & $60 \times 30.2 \times 0.508$ \\
\hline [18] & $28 \mathrm{GHz}$ & $27.4-28.6$ & 5.39 & $17.25 \times 5 \times 0.8$ & $27.4-28.6$ & 12 & $1 \times 8$ & $130 \times 60 \times 0.8$ \\
\hline [19] & $28 \mathrm{GHz}$ & $26-31$ & 4 & $15 \times 5 \times 0.4$ & $26-31$ & 16 & $1 \times 8$ & $15 \times 5 \times 0.8$ \\
\hline [20] & $28 \mathrm{GHz}$ & $25-40$ & 13 & $59 \times 8 \times 0.508$ & - & - & & - \\
\hline [21] & $28 \mathrm{GHz}$ & $10-40$ & 12 & $79.9 \times 24 \times 0.254$ & - & - & & - \\
\hline Proposed & $28 / 38 \mathrm{GHz}$ & $25-40$ & 13 & $73.4 \times 19.3 \times 0.203$ & $25-40$ & 16 & $1 \times 4$ & $135 \times 97.5 \times 0.203$ \\
\hline
\end{tabular}
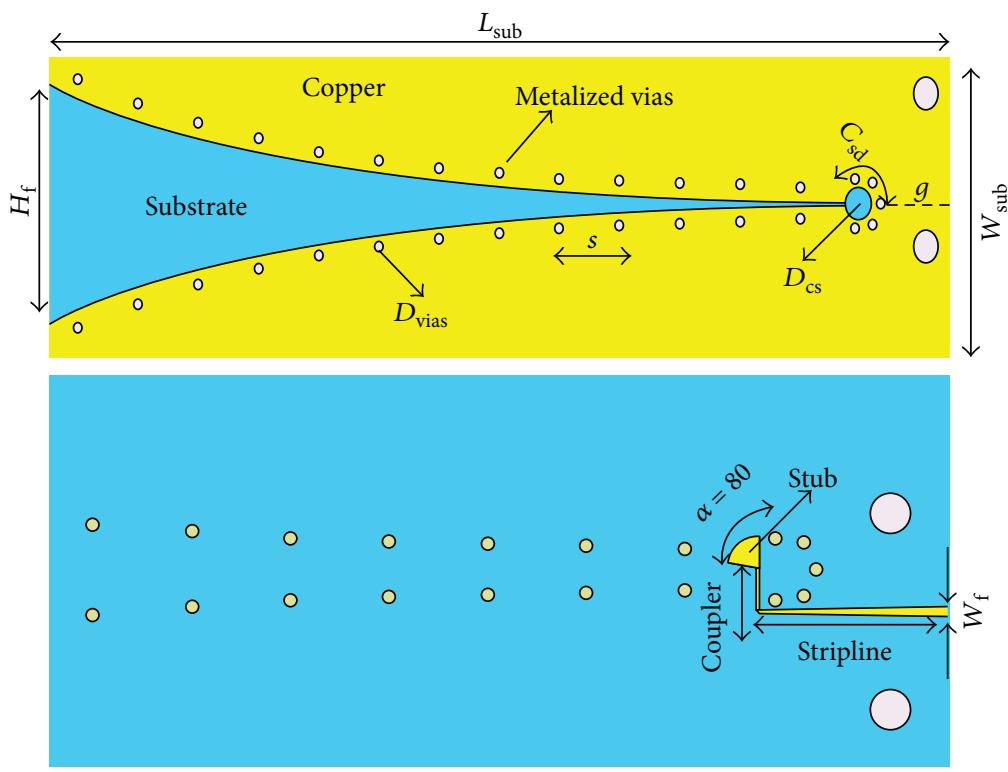

(a)

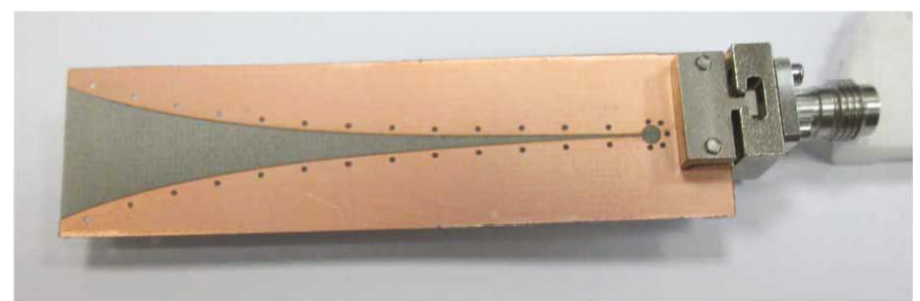

(b)

FIGURE 1: (a) Geometric design (top and bottom) of the proposed single-element SCVA. (b) Realized prototype of SCVA (top view).

more pronounced at the mmW band. In [7], authors used a planar antipodal fermi tapered slot array antenna in the frequency band of $27-32 \mathrm{GHz}$ in order to reduce mutual coupling among two antenna elements. The design has the features of having wide bandwidth and low isolation and side lobe levels with an average gain of $15 \mathrm{dBi}$. All this was achieved by introducing metamaterial corrugations on the edge of the tapered slot design. In [8], three patch antenna array designs were realized for the $28 \mathrm{GHz}$ band. Two among the three patch arrays were designed on a printed circuit board (PCB) material while one array design was made on low temperature co-fired ceramic (LTCC) to increase the gain and achieve wide bandwidth. The patch array designed on PCB offered a gain of $13 \mathrm{dBi}$ with a single resonance at $28 \mathrm{GHz}$ while the LTCC material array $(2 \times 2)$ achieved a gain of $10 \mathrm{dBi}$ with a wide bandwidth of $10.3 \%(26-29 \mathrm{GHz})$. In [9], the authors utilized the substrate integrated waveguide (SIW) technology to design a low-cost and high-gain antenna array for $5 \mathrm{G}$ communication. Slotted antennas in the shape of rectangles are designed on a substrate with permittivity of 2.2. The arrays of slots are placed in such a way that the E-field distribution can be controlled in order to get higher 


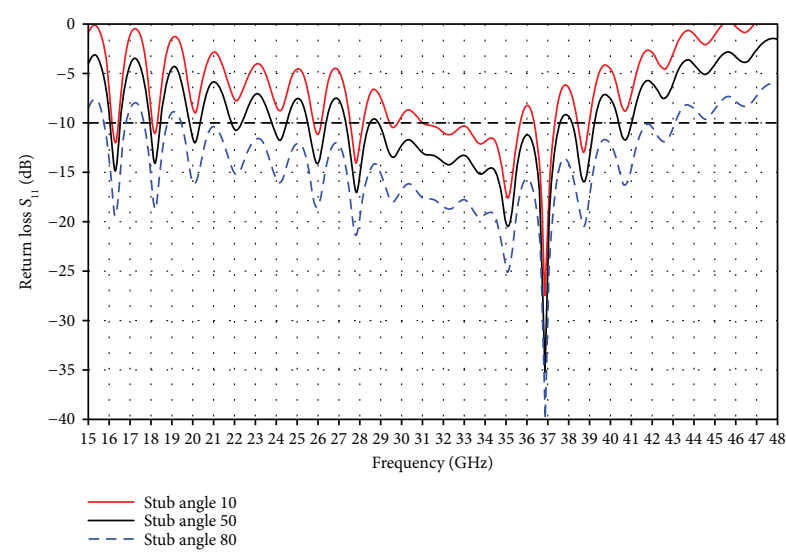

(a)

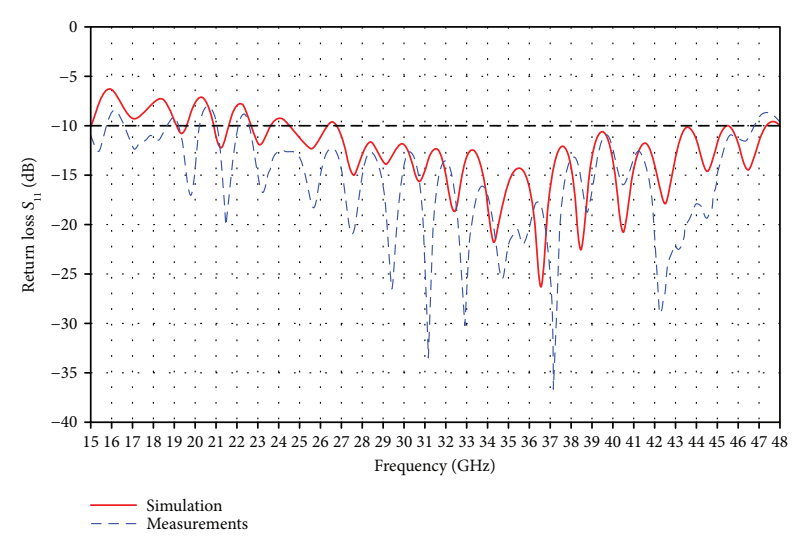

(b)

Figure 2: (a) Stub angle optimization. (b) Simulation and measured $S_{11}$ results of the proposed SCVA.

gain. The authors proposed a $3 \times 3$ element antenna array, which covers a bandwidth ranging from 28 to $36 \mathrm{GHz}$ and has a gain of $13.8 \mathrm{dBi}$ with $92 \%$ efficiency. In [10], the authors used a dielectric resonator antenna (DRA) array to achieve high gain at $28 \mathrm{GHz}$ band. A simple rectangular DRA array of $1 \times 4$ linear elements is designed and excited via various microstrip feeding techniques. The linear array of $1 \times 4$ DRA elements achieves an impedance bandwidth of $2.1 \mathrm{GHz}$ with a gain of $14 \mathrm{dBi}$.

All the aforementioned 5G designs are either achieving wider bandwidth or having higher gain, with relatively complex design. In this paper, we propose an array design for $5 \mathrm{G}$ communications by using Vivaldi antenna, which can cope with both requirements effectively. Vivaldi antenna is a tapered slot-type antenna, whose design is simple and offers light weight, compact size, and minimal cost of realization [11]. Vivaldi antenna has been extensively studied in literature with various design improvements [12-16].

For the problem at hand, we present a wide bandwidth and high-gain antenna array to operate over the standard $28 \mathrm{GHz}$ and $38 \mathrm{GHz}$ bands for $5 \mathrm{G}$ wireless communication systems. Initially, we propose and design a slot-coupled Vivaldi antenna (SCVA). Next, we design, fabricate, and characterize a complete $4 \times 4$ SCVA array unit cell, operating at the targeted $\mathrm{mmW}$ frequencies. The proposed antennas are designed using the low-loss tangent material RO4003 substrate and enjoys a gain $>20 \mathrm{dBi}$ and a wide bandwidth from 25 to $40 \mathrm{GHz}$ covering frequencies of interest at $28 \mathrm{GHz}$ and $38 \mathrm{GHz}$. The performance of the proposed array is further evaluated with respect to reception of various wirelessly transmitted standard digital modulation schemes. The performance is presented in terms of signal constellation diagrams and bit error rate (BER) values at various input power levels. Characteristic comparison of our design with various Vivaldi antennas is listed in Table 1. It can be seen in Table 1 that our proposed Vivaldi designs (single element and array) offer comparable and even better performance in terms of gain, dimensions, and bandwidth at the standard 5G communication bands.
TABLE 2: Optimized parameters of the proposed SCVA [24].

\begin{tabular}{lc}
\hline Parameters & Value $(\mathrm{mm})$ \\
\hline Substrate length $L_{\text {sub }}$ & 73.4 \\
Substrate width $W_{\text {sub }}$ & 19.3 \\
Feed width $W_{\mathrm{f}}$ & 0.47 \\
Stripline length & 9.43 \\
Coupler length & 2.1 \\
Stub radius & 1.56 \\
Stub angle, $\alpha$ & $80^{\circ}$ \\
Via dimeter, $D_{\text {vias }}$ & 0.6 \\
Spacing among vias, $s$ & 4.8 \\
Circular slot vias spacing, $C_{\text {sd }}$ & 1.4 \\
Start gap of circular slot, $g$ & 13.4 \\
Flare opening, $H_{\mathrm{f}}$ & 15.16 \\
Circular slot diameter, $D_{\mathrm{cs}}$ & 2 \\
\hline
\end{tabular}

\section{Slot-Coupled Vivaldi Antenna (SCVA)}

2.1. The Single Antenna Element. The bandwidth and gain of a single antenna element play an important role in defining the characteristics of the corresponding antenna array system. Various types of antennas offering wide bandwidth and high gain have been discussed in literature, including the dielectric rod antenna, spiral antenna, horn antenna, and log periodic antenna [22-25]. Perhaps the most popular type is Vivaldi antenna, also known as the tapered slot antenna (TSA) [26]. This antenna has a flared slot line aperture similar to the flared horn waveguide, which is the basis for its attractive features such as the wide bandwidth, low value of VSWR $(<2)$, and high gain for large arrays. Moreover, Vivaldi antenna is mostly printed on substrates that are fed via stripline or microstrip technology, which makes it easily integrable with other wireless components and devices.

In this study, we first start with the design of SCVA. Here, we make use of the theoretical design results initially reported by the authors in [27]. For coherency of presentation, we briefly summarize these results but also add new results 


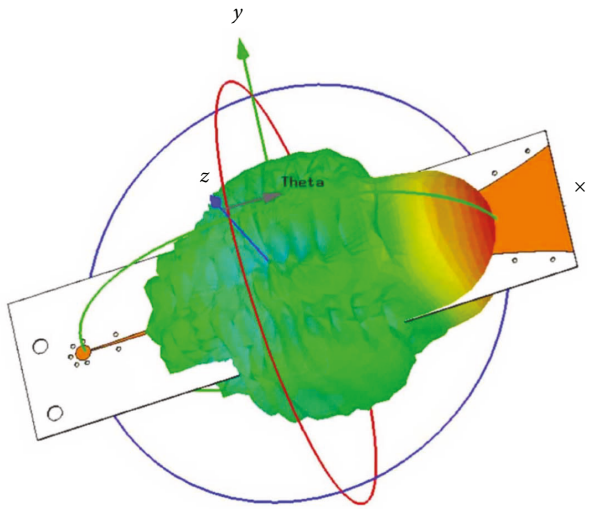

(a)
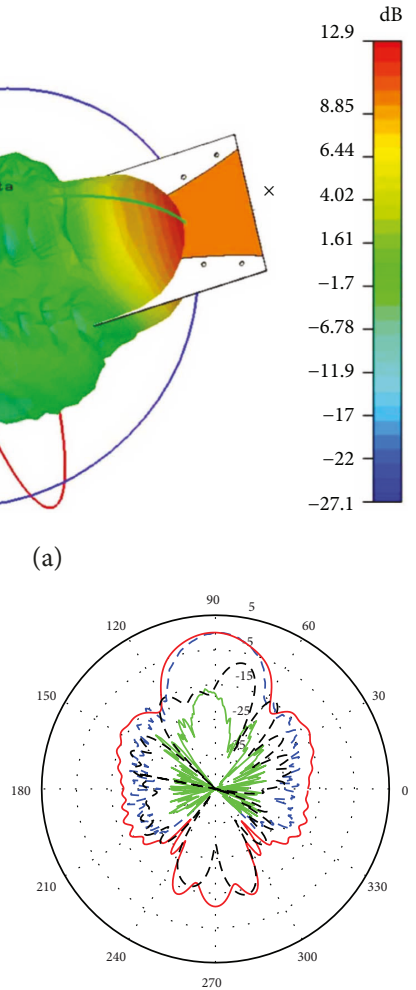

- Measurements cros

c)

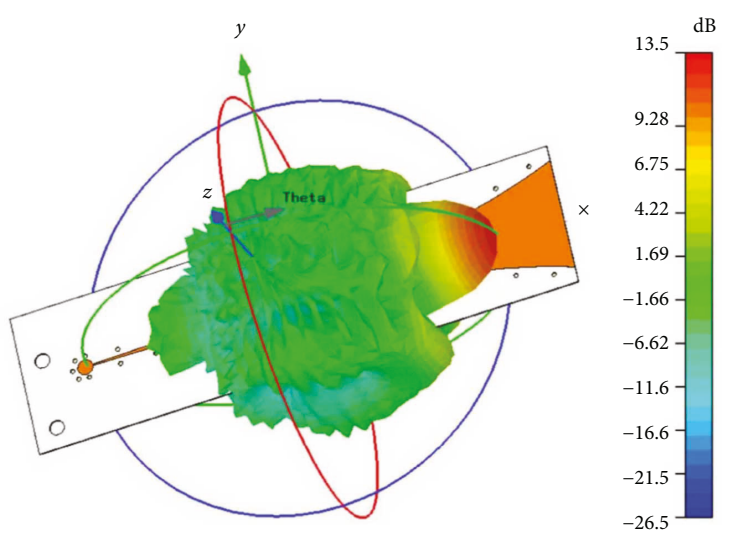

(b)

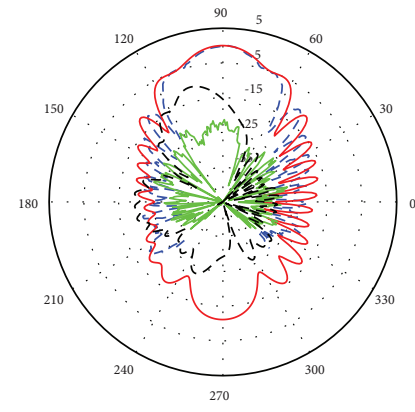

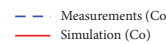

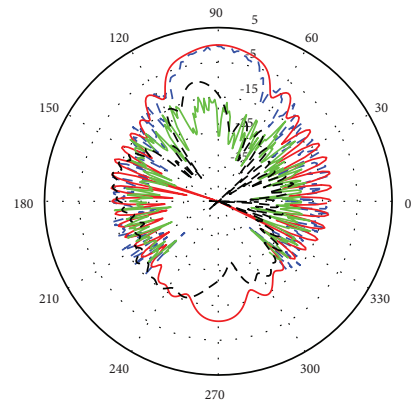

—- Measurements cross

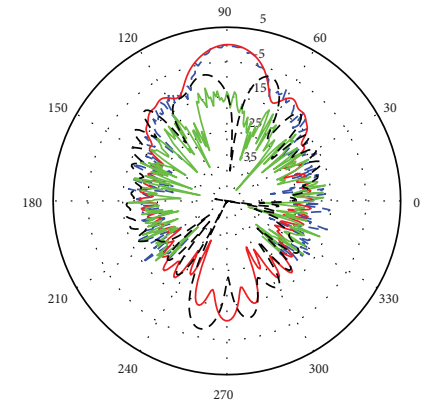

- Measurements $(\mathrm{Co})$
Simulation $(\mathrm{Co})$

(d)

FIGURE 3: 3D radiation pattern of the proposed antenna at (a) $28 \mathrm{GHz}$ with a gain of $12.9 \mathrm{dBi}$ and (b) $38 \mathrm{GHz}$ with a gain of $13.59 \mathrm{dBi}$. Simulated and measured E-plane (left side) and H-plane (right side) $2 \mathrm{D}$ radiation patterns at (c) $28 \mathrm{GHz}$ and (d) $38 \mathrm{GHz}$.

pertaining to the fabricated prototype. Configuration of the proposed SCVA is shown in Figure 1(a), while the realized structure is shown in Figure 1(b). The SCVA is printed on the top and bottom side of Rogers RO4003 substrate having permittivity of 3.55 , loss tangent of 0.0027 , and thickness of $0.203 \mathrm{~mm}$. The feed line conductor matched to a $50 \Omega$ impedance is on the back side of the substrate. The feed line follows a stripline-to-microstrip slot conversion using a radial stub. This technique provides a wide impedance bandwidth. The radial stub was varied at different angles $\left(0^{\circ}-90^{\circ}\right)$ with the optimum results presented in Figure 2(a). The exponential flare conductors of Vivaldi antenna are attached with a circular slot on the top side of the substrate. Both of them play a vital role and are responsible for the propagation of the waves in an end-fire directional plane. The exponential flare has contoured holes or vias along the tapered edges of the metalized conductors. These contours control and limit the radiation losses introduced in the SCVA [9]. The exponential profile of the antenna is characterized by the opening rate $R$, which is governed by the well-defined relations developed in [28]. The final optimized parameters for the proposed single-element SCVA are shown in Table 2.

Figure 2(b) presents the measured reflection coefficient $S_{11}$ of the single-element SCVA. The proposed antenna exhibits good impedance matching below $-10 \mathrm{~dB}$ over a wide bandwidth from 23 to $47 \mathrm{GHz}$. It also covers the $5 \mathrm{G}$ bands of interest, that is, $28 \mathrm{GHz}$ and $38 \mathrm{GHz}$. The normalized gain of

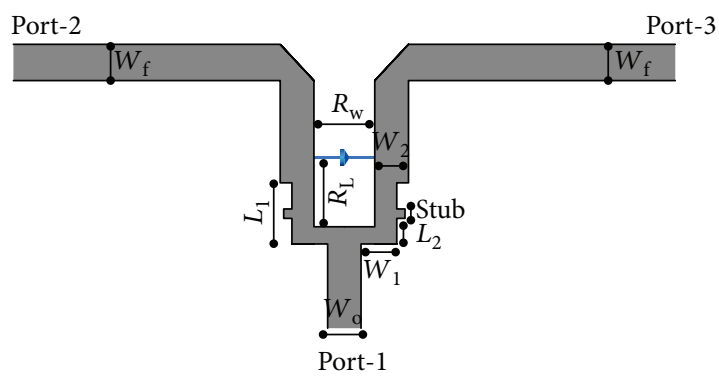

Figure 4: Geometric design of the single-section-modified WPD.

TABLE 3: Optimized parameters of the single-section-modified Wilkinson power divider with ports matched to $50 \Omega$ impedance.

\begin{tabular}{lc}
\hline Parameters & Value $(\mathrm{mm})$ \\
\hline$L_{1}$ & 0.7 \\
$L_{2}$ & 0.3 \\
$R_{\mathrm{L}}$ & 1.3 \\
$R_{\mathrm{W}}$ & 0.7 \\
$W_{\mathrm{o}}$ & 0.39 \\
$W_{1}$ & 0.4 \\
$W_{2}$ & 0.2 \\
Stub & 0.1 \\
\hline
\end{tabular}




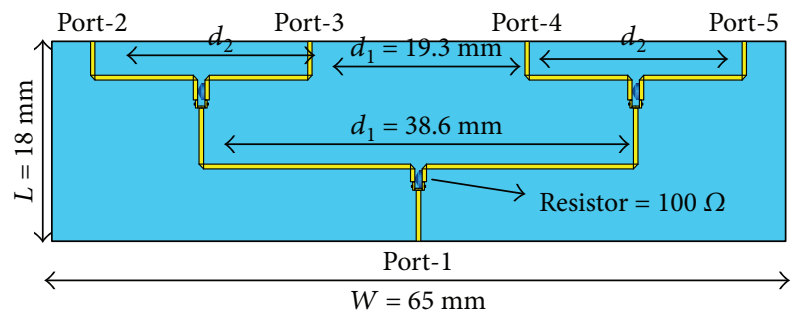

(a)

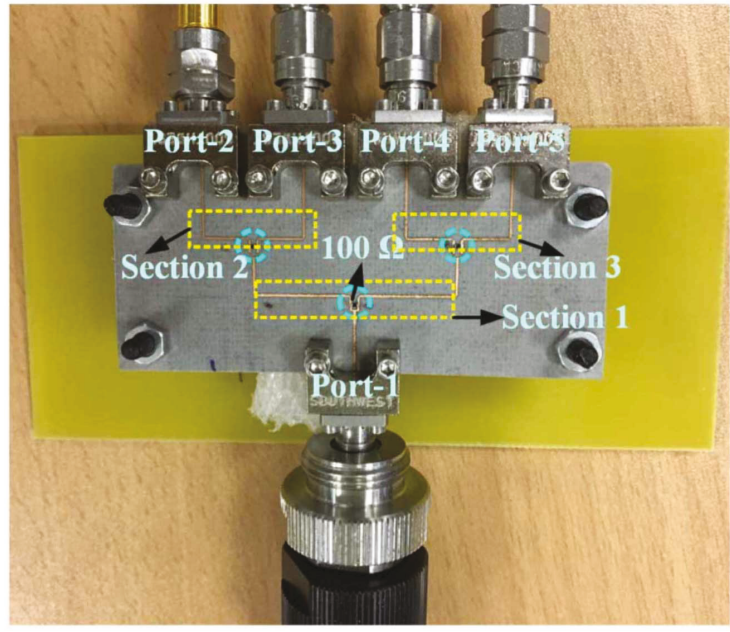

(b)

Figure 5: (a) Geometric design and dimensions of M3WPD. (b) Realized prototype of the M3WPD.

$3 \mathrm{D}$ radiation pattern and measured $2 \mathrm{D}$ polar plots are shown in Figures 3(a) and 3(b) for the proposed frequencies of $28 \mathrm{GHz}$ and $38 \mathrm{GHz}$. It can be observed from the 3D figure that the gain of the antenna is $12.9 \mathrm{dBi}$ and $13.5 \mathrm{dBi}$ in the end-fire direction, according to the $2 \mathrm{D}$ E-plane and $\mathrm{H}$ plane polar plots of radiation pattern. For $28 \mathrm{GHz}$ frequency, the E-plane has a side lobe level of $-10.4 \mathrm{~dB}$ and angular beam width of $27.8^{\circ}$ while the $\mathrm{H}$-plane has a side lobe level of $-10.5 \mathrm{~dB}$ and angular beam width of $30.8^{\circ}$. Similarly, at $38 \mathrm{GHz}$, the E-plane has a side lobe level of $-7.7 \mathrm{~dB}$ and angular beam width of $33.9^{\circ}$ while the $\mathrm{H}$-plane has a side lobe level of $-9.3 \mathrm{~dB}$ and angular beam width of $23.3^{\circ}$.

2.2. The Feed Network. The single-element SCVA is used to construct a higher gain $1 \times 4$ linear array. This array is fed with a corporate feed network. Here, we consider Wilkinson power divider (WPD), which can reasonably deliver maximum power to the radiating elements of the array, offer good isolation among the ports, and provide wide bandwidth characteristics [29]. Note that adding cascaded sections to WPD's output ports or using PCB multilayer technology increases the bandwidth of WPD at the expense of increasing circuit dimensions, which in turn, presents poor insertion loss [30, 31]. For size compactness, this work considers the stepped impedance open circuit radial stub technology, where a modified three-section Wilkinson power divider (M3WPD) is used in the design of $1 \times 4$ linear array [32]. Figure 4 shows the design of a single section of the M3WPD, which contains a small square stub matched to each of its branch lines. A $100 \Omega$ thick film resistor, with part number 0402 produced by Vishay electronics, is placed at the output ports (port-2 and port-3) to isolate the power delivered to these two ports by the input port (port-1). The optimized parameters for the single section WPD are presented in Table 3.

Figure 5 shows the geometric dimensions and fabricated M3WPD, where Rogers RO4003 is again used as a substrate in both simulation and fabrication. The performance characteristics of fabricated M3WPD are measured using Agilent Technologies network analyzer N5227A that is operational from $10 \mathrm{MHz}$ to $67 \mathrm{GHz}$. The simulated and measured results are shown in Figure 6, where we observe that reflection coefficient $S_{11}$ through $S_{55}$ is below $-10 \mathrm{~dB}$ over a wide range of $\mathrm{mmW}$ spectrum covering the bands of interest at $28 \mathrm{GHz}$ and $38 \mathrm{GHz}$. Figure 6(a) shows simulated results of reflection coefficient from port-1 to port-5. Figure 6(b), on the other hand, shows the insertion loss and mutual coupling among the ports. The transmission coefficients with respect to port 1 , that is, $S_{12}, S_{13}, S_{14}$, and $S_{15}$, have values around $-7 \mathrm{~dB}$ at $28 \mathrm{GHz}$ and $38 \mathrm{GHz}$. Theoretically, the measured transmission coefficient values fall in the range of $-6 \mathrm{~dB}$ up to $-7 \mathrm{~dB}$. This condition is well satisfied at the $28 \mathrm{GHz}$ frequency band. However, due to fabrication tolerances and manual insertion of discrete components that might become very critical at higher frequencies, we have found additional losses up to $4 \mathrm{~dB}$ as can be seen in Figure $6(\mathrm{~d})$ at $38 \mathrm{GHz}$. The mutual coupling among the output ports, specifically for the neighboring ports, should be as minimum as possible. We have found from the S-parameter measurements that $S_{23}$, $S_{34}$, and $S_{45}$ (presenting mutual coupling between ports 2-3, ports 3-4, and ports $4-5$, resp.) are well below $-15 \mathrm{~dB}$ over the desired bandwidths (Figure 6(d)). By virtue of the measurement results, we observe that the M3WPD offers good isolation among ports and has wide bandwidth, which makes it a good feeding network for the $1 \times 4$ Vivaldi antenna array.

2.3. The $1 \times 4$ Linear Vivaldi Array. The optimized singleelement SCVA and optimized M3WPD feeding network are integrated together to construct a $1 \times 4$ linear array. Antenna arrays can have higher gain and directivity with narrower beam width compared to single antenna elements. In general, the larger the number of individual antenna elements is, the higher the gain and the narrower the beam width are $[33,34]$. 

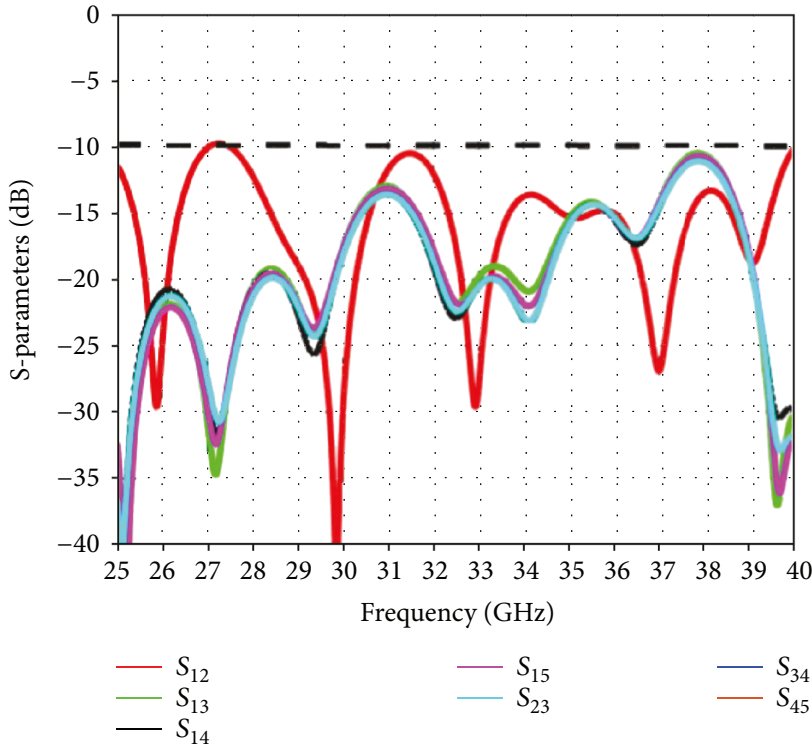

(a)

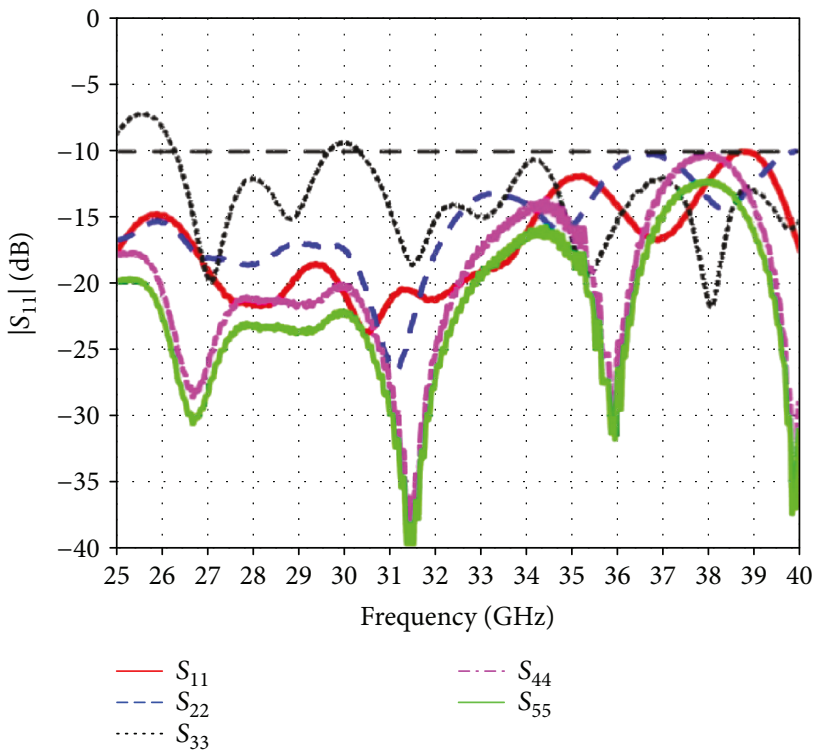

(c)

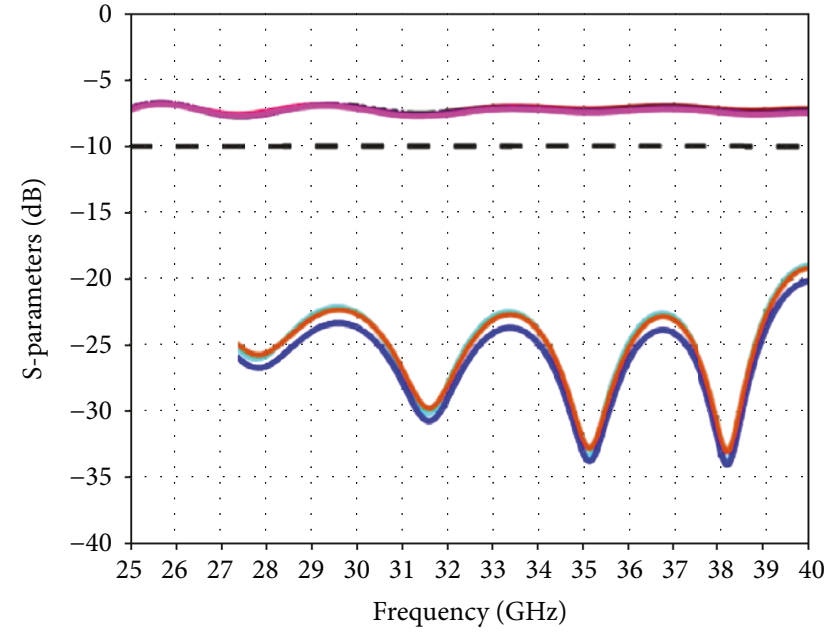

$-S_{12}$
$-S_{13}$
$-S_{14}$

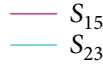

$-S_{34}$

(b)

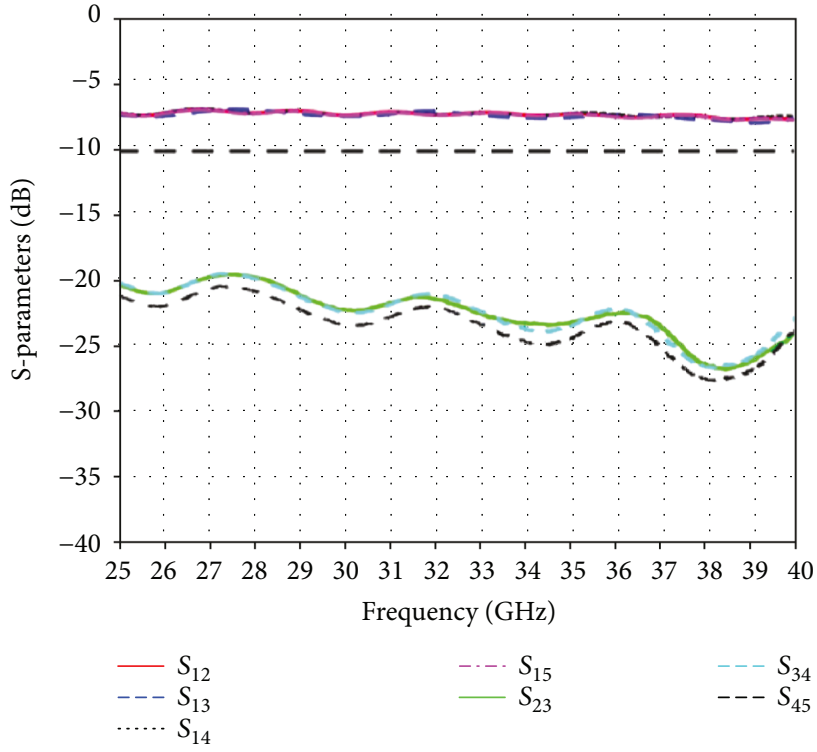

(d)

Figure 6: Simulated results of the $1 \times 4$ WPD (a) return loss $\left(S_{11}\right)$ and (b) insertion loss and isolation among ports. Measured results of the $1 \times 4 \mathrm{WPD}(\mathrm{c})$ reflection coefficients and $(\mathrm{d})$ insertion loss and isolation among ports.

Figure 7 shows the geometric design of the antenna array, while Figure 8 shows the realized prototype. The original conductor or radiating element on the top side has a dimension of $L_{\mathrm{c}} \times W_{\mathrm{c}}$ while the substrate has a dimension of $L_{\mathrm{s}} \times W_{\mathrm{s}}$. The extra extension $G_{\mathrm{x}}(25 \mathrm{~mm})$ in the design achieves a small increase in gain (around $0.5 \mathrm{dBi}$ ) and also assists in packaging the $4 \times 4$ unit cell in a transparent box, as will be discussed in the next section. The backside of the substrate has the M3WPD. The optimized dimensions of the linear array are presented in Table 4.

Figure 9 shows the simulated and measured S-parameters and gain of the proposed $1 \times 4$ linear Vivaldi antenna array. The antenna array is resonating in the required $\mathrm{mmW}$ spectrum, covering a wide range from 25 to $40 \mathrm{GHz}$. Also, it has a maximum realized gain, in the principle E-plane, above $15 \mathrm{dBi}$ over a flat bandwidth range. The normalized $2 \mathrm{D}$ polar plots of the measured radiation pattern at the center frequencies of $28 \mathrm{GHz}$ and $38 \mathrm{GHz}$ are shown in Figure 10 . The $3 \mathrm{D}$ radiation pattern of the antenna array is shown in Figure 11. Referring to the figure, the array is highly directional with a gain of more than $15 \mathrm{dBi}$ in the end-fire direction. The E-plane and $\mathrm{H}$-plane responses of the array are observed from the 2D polar plots. For the frequency of $28 \mathrm{GHz}$, the E-plane has a side lobe level of $-8.8 \mathrm{~dB}$ and an angular beam width of $6.7^{\circ}$, while the $\mathrm{H}$ plane offers a side lobe level of $-9.6 \mathrm{~dB}$ and angular beam 


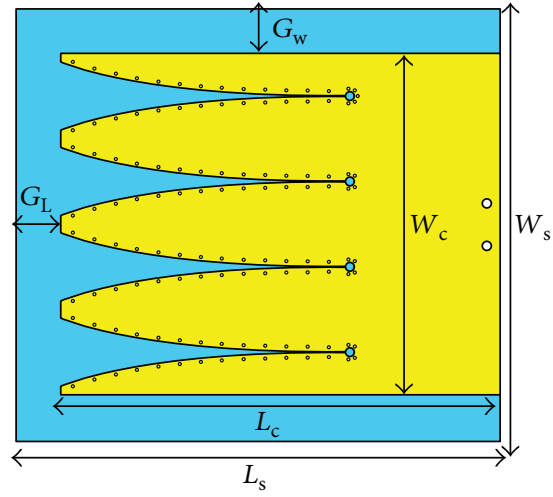

(a)

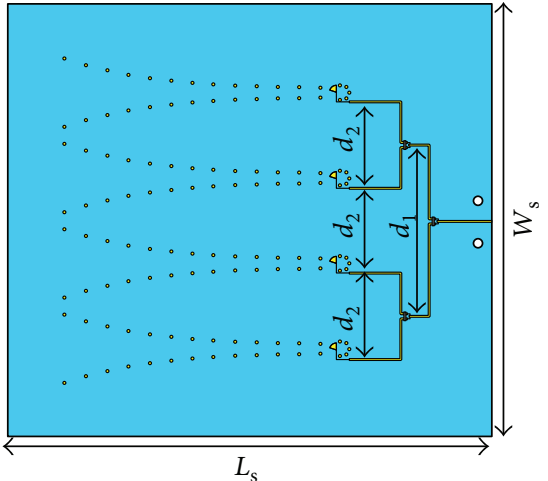

(b)

Figure 7: Geometric design of the $1 \times 4$ linear Vivaldi array antenna. (a) Top plane view and (b) back plane view.

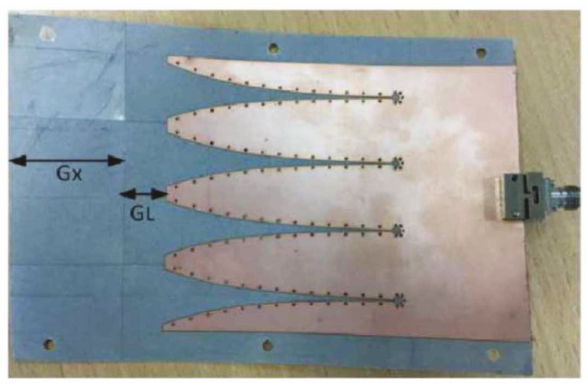

(a)

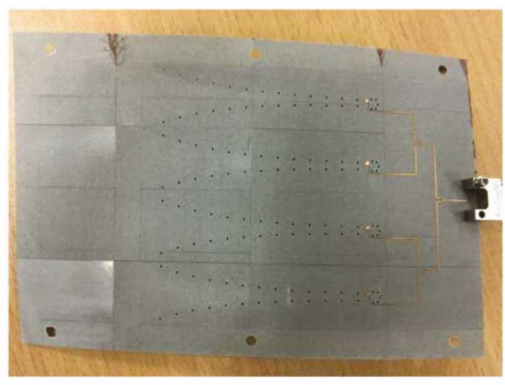

(b)

FIGURE 8: Realized prototype of the $1 \times 4$ linear Vivaldi array integrated with WPD acting as feed network. (a) Top plane view and (b) back plane view.

TABLE 4: Optimized parameters of the $1 \times 4$ linear Vivaldi antenna array.

\begin{tabular}{lc}
\hline Parameters & Value $(\mathrm{mm})$ \\
\hline$L_{\mathrm{c}}$ & 99 \\
$L_{\mathrm{s}}$ & 135 \\
$W_{\mathrm{c}}$ & 77 \\
$W_{\mathrm{s}}$ & 97.5 \\
$G_{\mathrm{w}}$ & 11.4 \\
$G_{\mathrm{L}}$ & 13 \\
$G_{\mathrm{x}}$ & 25 \\
$d_{1}$ & 38.6 \\
$d_{2}$ & 19.3 \\
\hline
\end{tabular}

width of $29.1^{\circ}$. Similarly, for the $38 \mathrm{GHz}$ frequency, the Eplane has a side lobe level of $-8.4 \mathrm{~dB}$ and an angular beam width of $5^{\circ}$, while the $\mathrm{H}$-plane offers a side lobe level of $-8.2 \mathrm{~dB}$ and an angular beam width of $33.1^{\circ}$. The beam width is quite narrow in the E-plane as compared to the H-plane.

\section{3. $4 \times 4 \mathrm{mmW}$ Antenna Array Unit Cell}

3.1. S-Parameters and Mutual Coupling. The previously designed and experimentally verified $1 \times 4$ linear Vivaldi

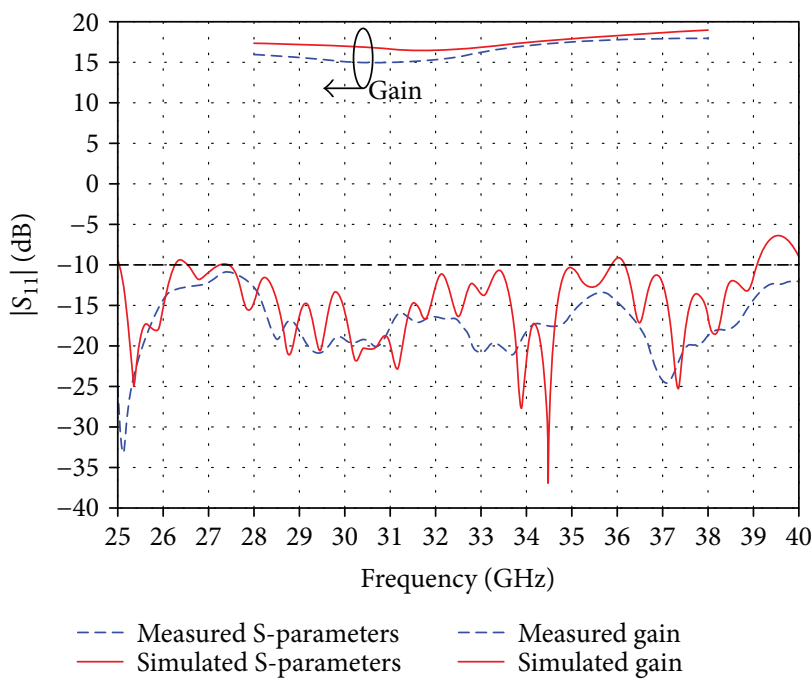

Figure 9: Simulated and measured reflection coefficient $S_{11}$ of proposed $1 \times 4$ linear array.

antenna array is used to construct a $4 \times 4$ antenna array unit cell inside an acrylic portable box. Figure 12(a) shows the layout of placement of arrays, while Figure 12(b) shows the final prototype. The CST MWS [35] array synthesis tool is used to calculate the radiation performance of the cell array. At the optimum distance $\left(D_{\text {space }}\right)$ of $14 \mathrm{~mm}$, the unit 


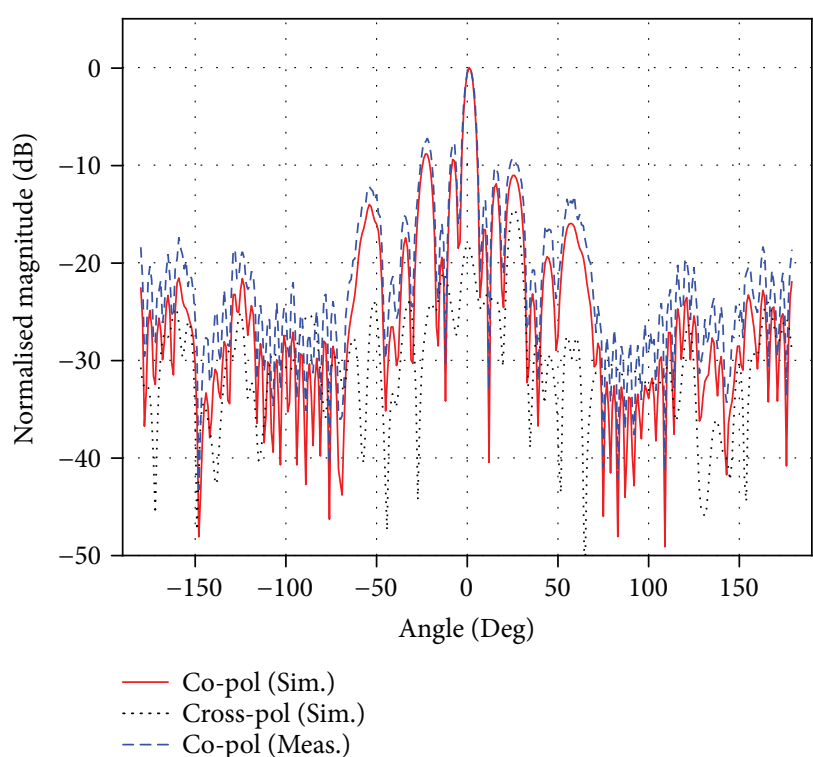

(a)

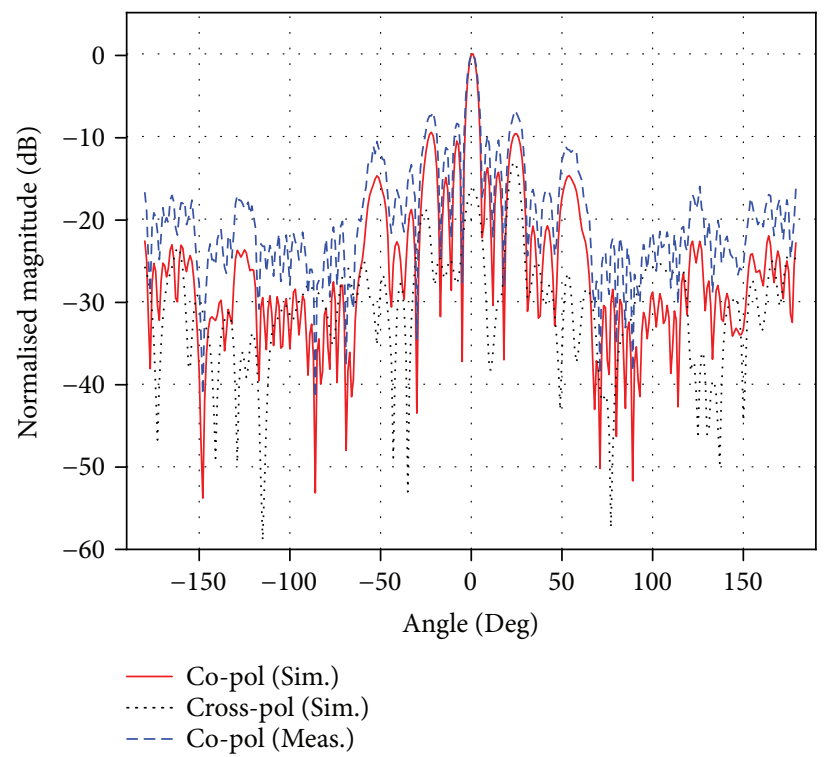

(c)

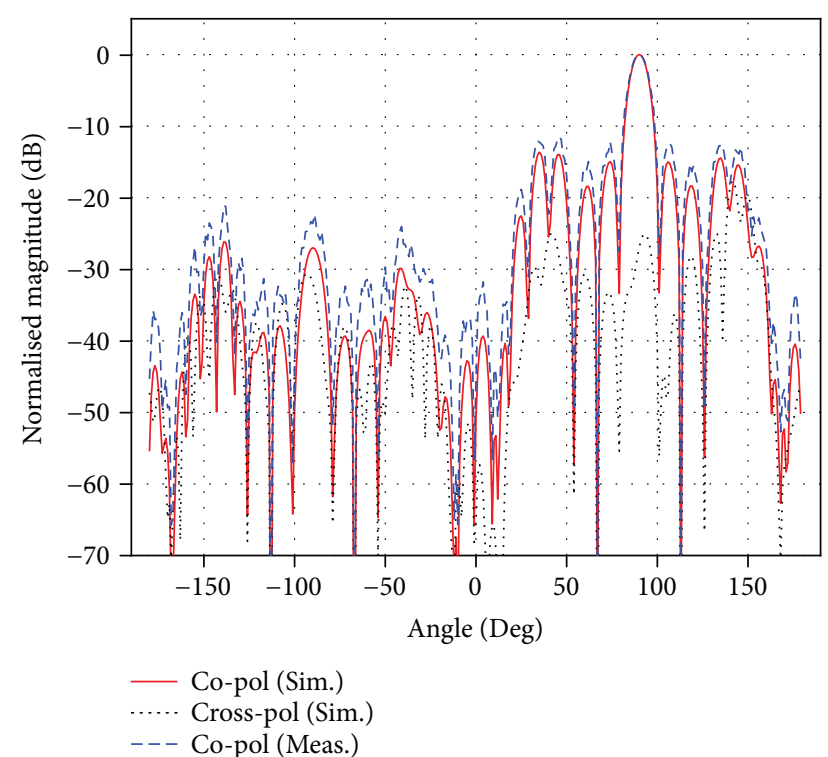

(b)

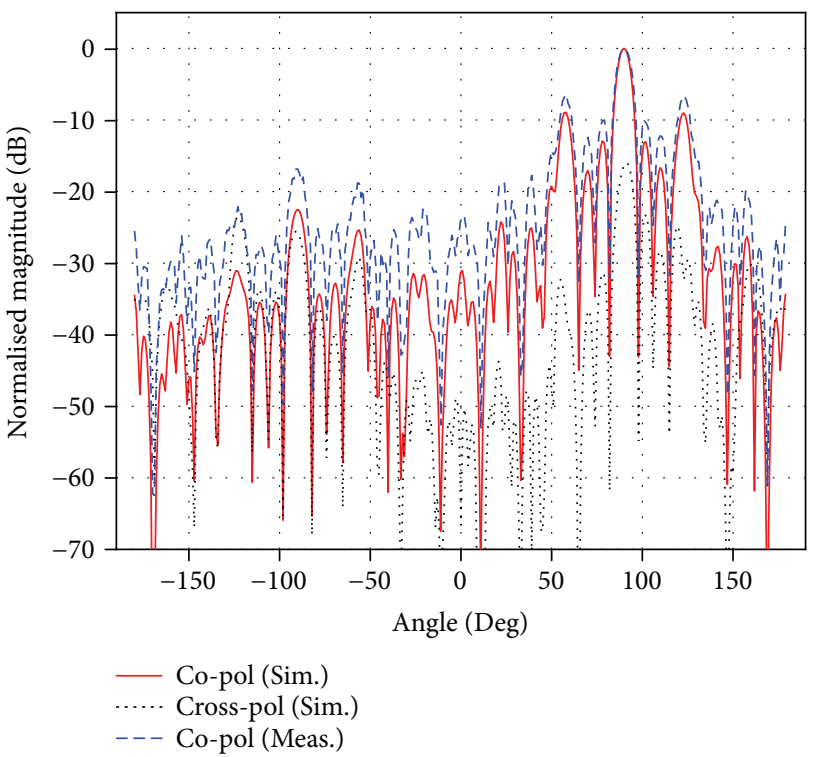

(d)

Figure 10: Measured Co-pol radiation patterns of the $1 \times 4$ linear Vivaldi antenna array. (a) E-plane $28 \mathrm{GHz}$. (b) H-plane $28 \mathrm{GHz}$. (c) E-plane $38 \mathrm{GHz}$. (d) H-plane $38 \mathrm{GHz}$.

cell achieves a high gain of $22.4 \mathrm{dBi}$ and $23.5 \mathrm{dBi}$ at $28 \mathrm{GHz}$ and $38 \mathrm{GHz}$, respectively. Figure 13 shows the $3 \mathrm{D}$ radiation pattern of the $4 \times 4 \mathrm{mmW}$ array unit cell at the frequencies of interest.

Figure 14 shows the measured mutual coupling between the different array ports. These measurements are performed before integrating the M3WPD with the array. It can be seen from the measured results of Figure 14 that the reflection coefficients of the individual ports $S_{11}, S_{22}$, $S_{33}$, and $S_{44}$ have resonance below $-10 \mathrm{~dB}$ at both the frequencies of interest. Also, the mutual coupling among ports, that is, $S_{12}, S_{13}, S_{14}$, and $S_{23}$ is well below $-20 \mathrm{~dB}$. Figure 15, on the other hand, shows the return loss $S_{11}$ after integrating the M3WPD with the $4 \times 4$ array. It can be observed from the figure that the antenna radiates well below $-10 \mathrm{~dB}$ over wide impedance bandwidths in the range from 25 to $40 \mathrm{GHz}$.

3.2. Array Performance in Wireless Communication. For further performance evaluation of the developed $4 \times 4$ array, an experimental setup is made for the transmission and reception of standard digital modulation formats over a wireless link. The block diagram of the setup is shown in Figure 16. At the transmission end, an arbitrary waveform generator (AWG), model number M8190, from Keysight with a sampling rate of $12 \mathrm{GSa} / \mathrm{s}$ is used to generate the baseband I- and Q-modulated signals with a system baud rate of $500 \mathrm{MHz}$. A MATLAB open source kit, called Keysight IQ 


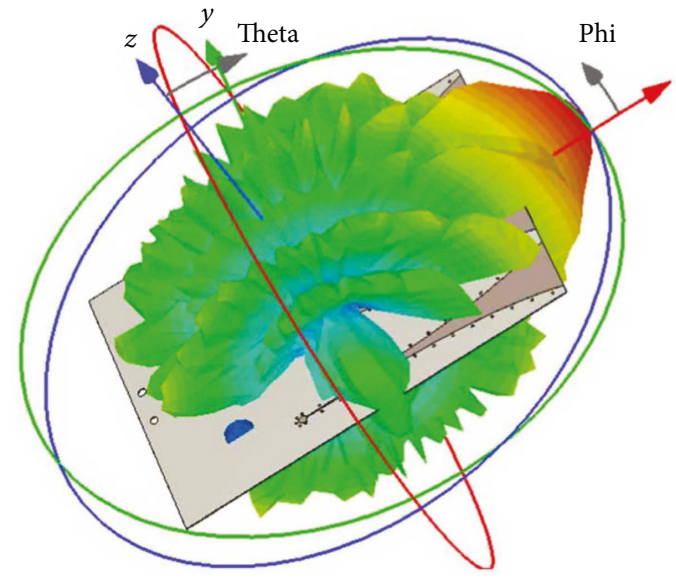

(a)
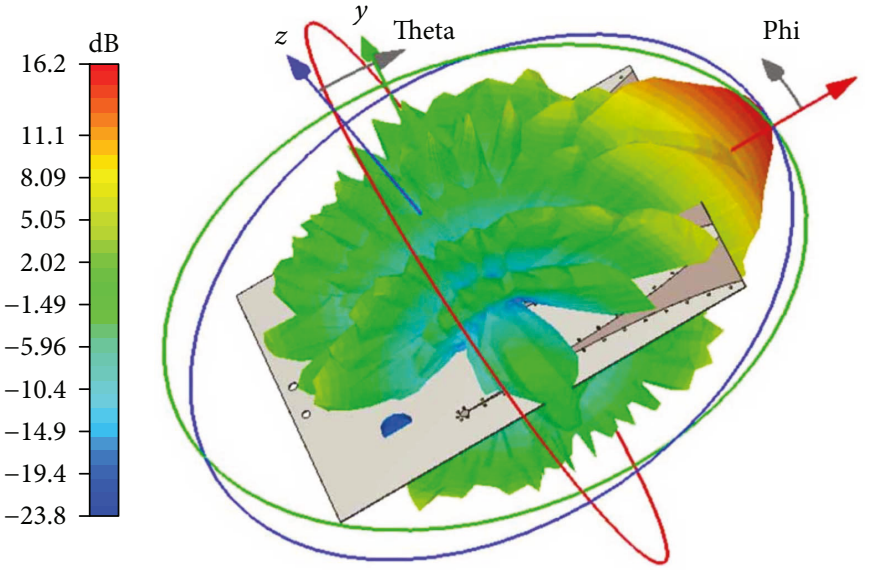

(b)

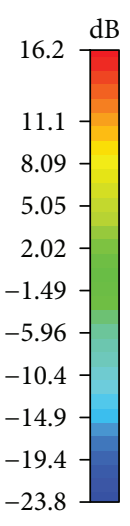

Figure 11: 3D gain of the proposed $1 \times 4$ linear Vivaldi antenna array at $28 \mathrm{GHz}$ and $38 \mathrm{GHz}$.

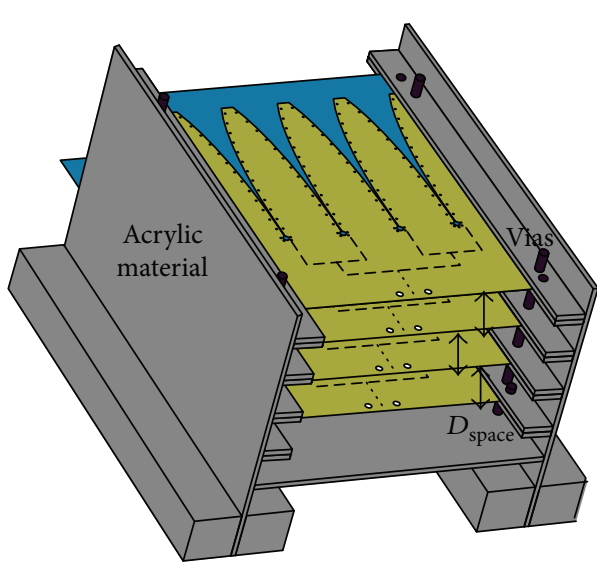

(a)

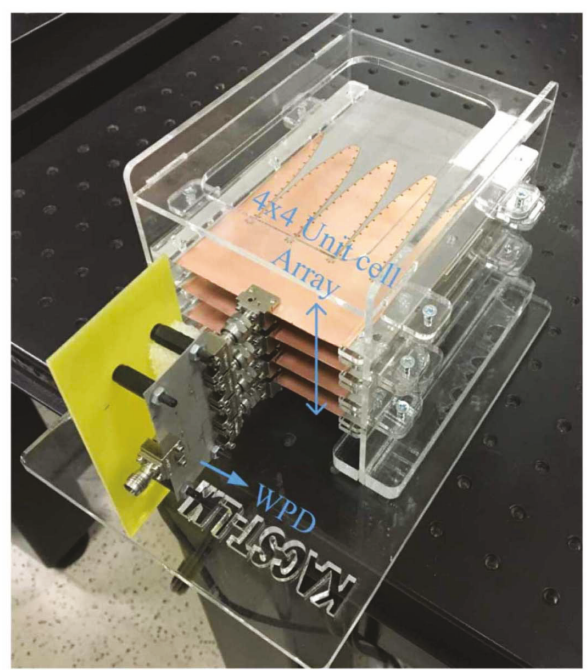

(b)

FIgURE 12: (a) Layout of acrylic box for placement of four $1 \times 4$ antenna arrays. (b) Prototype of the $4 \times 4$ antenna array unit cell.

Tools, is used to implement the modulation techniques considered in this work. The baseband I/Q signals are sent through RF coaxial cables to the Keysight vector signal generator (VSG), model number E8267D, which works as an upconverter. Note that PSG applies a carrier offset to set the carrier frequency to the desired value. Moreover, it allows variation in the output power levels of transmitted signals from below $-100 \mathrm{dBm}$ up to $27 \mathrm{dBm}$. For a given fixed distance between the transmitting and receiving antennas, these features of PSG facilitate studying the array performance for the reception of different modulation schemes against variable-transmitted signals' strengths. In this setup, the RF output of PSG is transmitted using a horn antenna with a gain of $25 \mathrm{dBi}$. The horn antenna is the product of NSI-MI Company, with a bandwidth of $26.5-40 \mathrm{GHz}$. The distance between the transmitting and receiving antennas is kept constant at $1.5 \mathrm{~m}$. For this experimental setting at $28 \mathrm{GHz}$, this distance is in the far field and aligns with the range of distances previously considered in the literature [36, 37].

At the receiver side, the unit cell receives the transmitted modulation and displays the result on the digital storage oscilloscope of $80 \mathrm{GSa} / \mathrm{s}$ (Keysight DSO-X 93204A). The received signal is demodulated using the Keysight vector signal analyzer (VSA). Figure 17 shows the experimental results in the form of estimated BER for different modulation schemes versus transmitted/received power. The BER is inferred from the measured error vector magnitude (EVM). For a wireless distance of $1.5 \mathrm{~m}$, we have a minimum receiver sensitivity of $-53 \mathrm{dBm},-50.7 \mathrm{dBm}$, and $-50 \mathrm{dBm}$ for 16 QAM, 32 QAM, and OFDM-16 QAM, respectively, with BER below the forward error correction (FEC) limit. Also, a maximum successful wireless transmission of $2.5 \mathrm{Gbps}$ data 


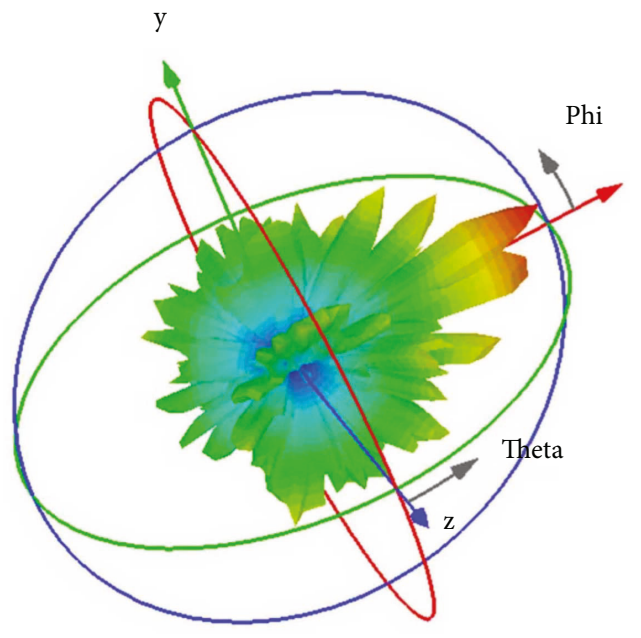

(a)
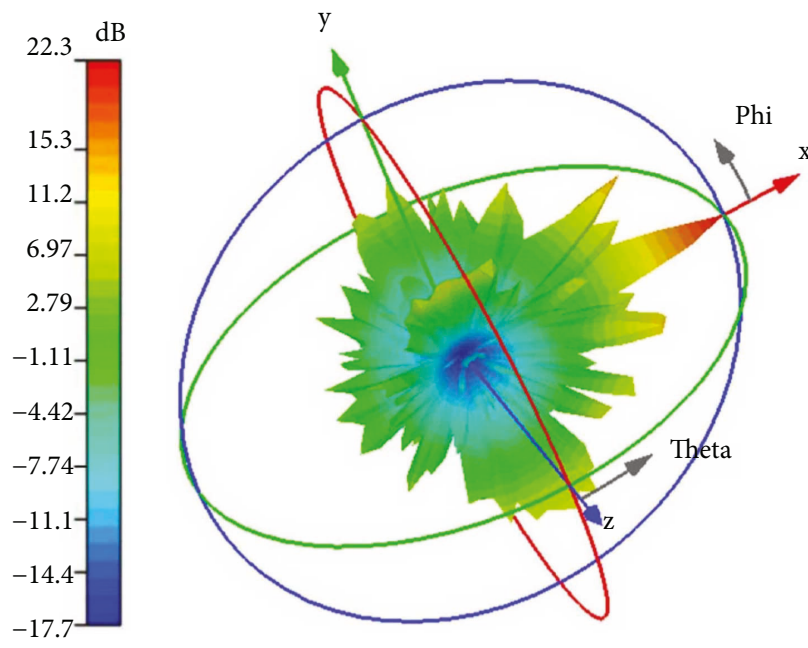

(b)

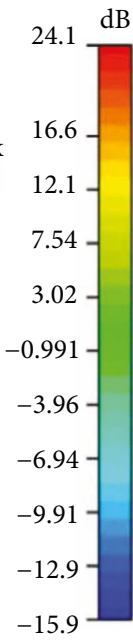

Figure 13: 3D radiation pattern of the proposed $4 \times 4 \mathrm{mmW}$ array unit cell (a) with a $22.3 \mathrm{dBi}$ gain at $28 \mathrm{GHz}$ and (b) with a $24.1 \mathrm{dBi}$ gain at $38 \mathrm{GHz}$.

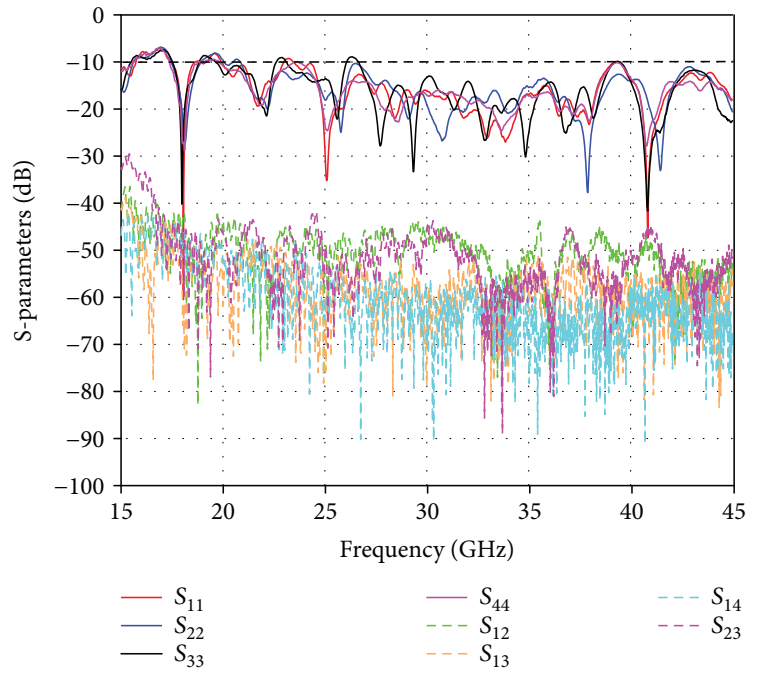

FIGURE 14: Measured S-parameters and mutual coupling of the $4 \times 4$ $\mathrm{mmW}$ array unit cell.

rate is achieved with BER of $2 \times 10^{-3}$ at $-50 \mathrm{dBm}$-received power. For further demonstration, Table 5 shows the received constellation diagrams for various modulation orders, at different transmitted power.

\section{Conclusion}

In this paper, a wide bandwidth and high-gain $4 \times 4$ antenna array unit cell is designed, fabricated, and tested for $5 \mathrm{G}$ wireless communication using an experimental testbed setup capable of generating standard digital modulation schemes over a carrier frequency of $28 \mathrm{GHz}$. The design of the proposed antenna array is based on a single SCVA, which has a wide impedance bandwidth from 25 to $40 \mathrm{GHz}$ and high

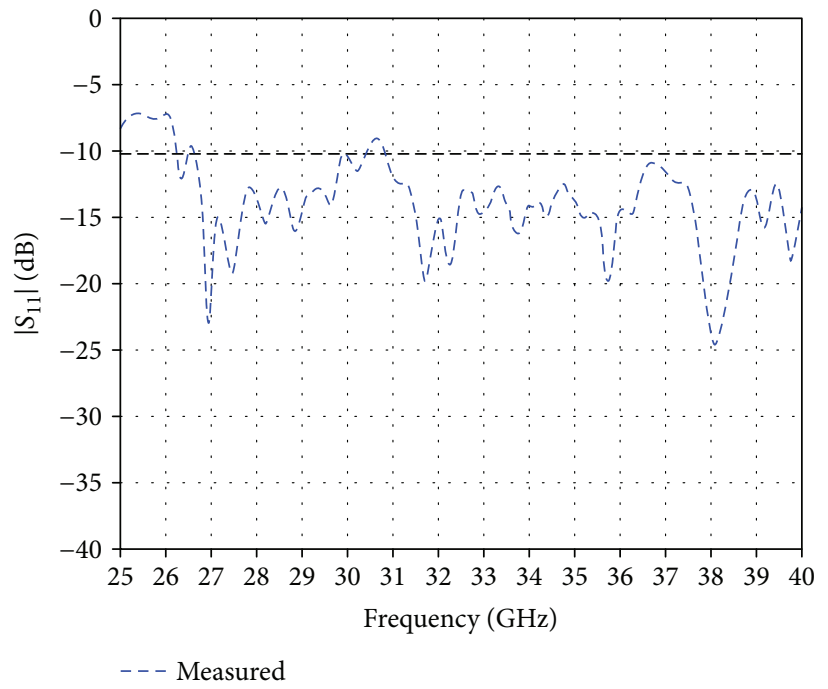

Figure 15: Measured reflection coefficient $S_{11}$ of the $4 \times 4 \mathrm{mmW}$ unit cell when connected to the modified WPD.

gain with a value up to $13 \mathrm{dBi}$. The proposed $4 \times 4$ antenna array consists of four $1 \times 4$ SCVA linear arrays. Therefore, a M3WPD is designed, fabricated, and characterized for the purpose of operating as a corporate feed network for each $1 \times 4$ array. It has been demonstrated experimentally that the M3WPD provides wide bandwidth and good isolation among the input and output ports in the bands of interest. The $1 \times 4$ antenna array has an impedance bandwidth from 25 to $40 \mathrm{GHz}$ and a gain of $\sim 16 \mathrm{dBi}$ in the end-fire direction. However, the proposed $4 \times 4$ antenna array unit cell works at the dual frequencies $28 \mathrm{GHz}$ and $38 \mathrm{GHz}$ providing wide bandwidths from 25 to $40 \mathrm{GHz}$ and an average gain of $\sim 23 \mathrm{dBi}$. The wireless transmission and reception of various digital modulation schemes, as 


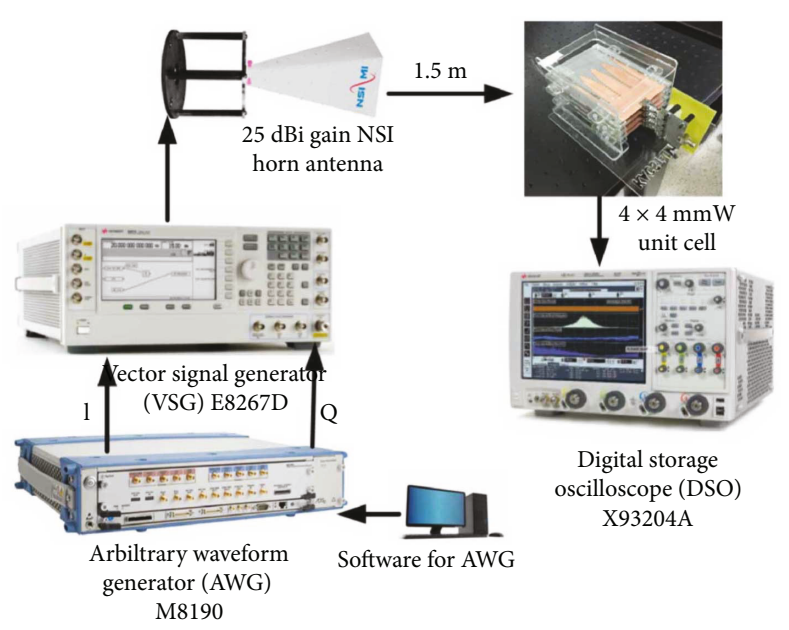

(a)

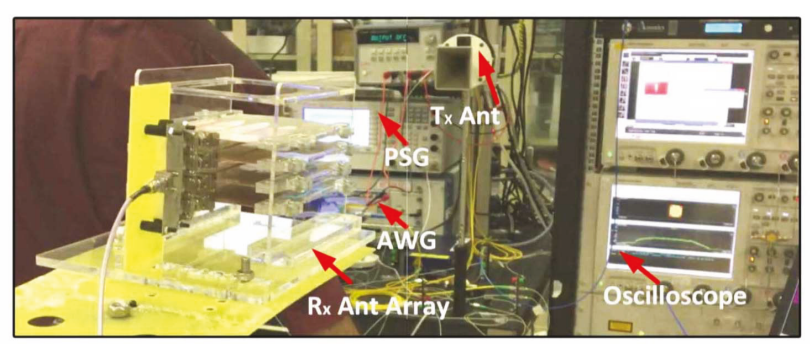

(b)

FIGURE 16: The proposed experimental setup. (a) Block diagram. (b) Measurements.

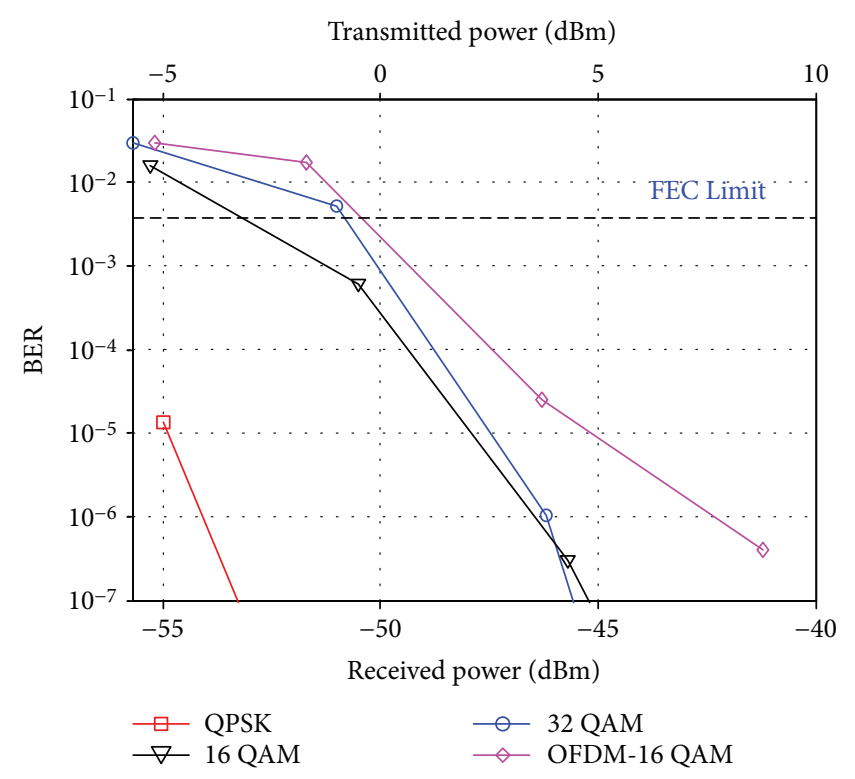

FIGURE 17: BER versus electrical received power for QPSK, 16QAM, 32QAM, and OFDM-16QAM at $1.5 \mathrm{~m}$ wireless distance.

presented in Section 3.2, have shown the promising evidence of the demonstrated unit cell as a candidate antenna array for next generation communication systems. A successful data transmission of $2.5 \mathrm{Gbps}$ is achieved with a receiver sensitivity of $-50 \mathrm{dBm}$ and over $1.5 \mathrm{~m}$ wireless distance.
TABLE 5: Received constellations for various modulation schemes and transmitted power levels.

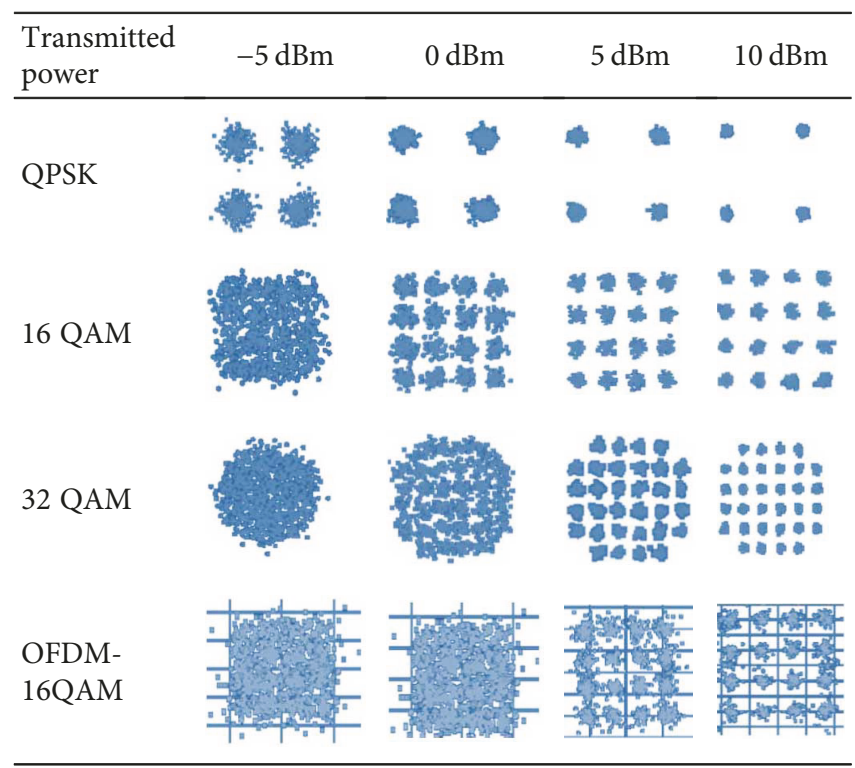

\section{Conflicts of Interest}

The authors declare that they have no conflicts of interest.

\section{Acknowledgments}

This research is supported in part by King Abdul Aziz City for Science and Technology and Lockheed Martin (KACST-LM) University Research Funding Program and Project 33-878.

\section{References}

[1] P. Gupta, "Evolvement of mobile generations: $1 \mathrm{G}$ to $5 \mathrm{G}$," International Journal for Technological Research in Engineering, vol. 1, pp. 152-157, 2013.

[2] T. S. Rappaport, Shu Sun, R. Mayzus et al., "Millimeter wave mobile communications for $5 \mathrm{G}$ cellular: it will work!," IEEE Access, vol. 1, pp. 335-349, 2013.

[3] Y. Huo, X. Dong, and W. Xu, "5G cellular user equipment: from theory to practical hardware design," 2017, http://arxiv. org/abs/1704.02540.

[4] M. A. Matin, "Review on millimeter wave antennas-potential candidate for 5G enabled applications," Advanced Electromagnetics, vol. 5, no. 3, pp. 98-105, 2016.

[5] W. Roh, J.-Y. Seol, J. Park et al., "Millimeter-wave beamforming as an enabling technology for $5 \mathrm{G}$ cellular communications: theoretical feasibility and prototype results," IEEE Communications Magazine, vol. 52, no. 2, pp. 106-113, 2014.

[6] N. Ojaroudiparchin, M. Shen, and G. F. Pedersen, “A $28 \mathrm{GHz}$ FR-4 compatible phased array antenna for $5 \mathrm{G}$ mobile phone applications," in 2015 International Symposium on Antennas and Propagation (ISAP), pp. 1-4, Hobart, TAS, Australia, 2015.

[7] S. Gupta, Z. Briqech, A. R. Sebak, and T. A. Denidni, "Mutualcoupling reduction using metasurface corrugations for $28 \mathrm{GHz}$ MIMO applications," IEEE Antennas and Wireless Propagation Letters, vol. 16, pp. 2763-2766, 2017. 
[8] K. S. Chin, H. T. Chang, J. A. Liu, H. C. Chiu, J. S. Fu, and S. H. Chao, "28-GHz patch antenna arrays with $\mathrm{PCB}$ and LTCC substrates," in Proceedings of 2011 Cross Strait QuadRegional Radio Science and Wireless Technology Conference, pp. 355-358, Harbin, China, 2011.

[9] W. Han, F. Yang, J. Ouyang, and P. Yang, "Low-cost wideband and high-gain slotted cavity antenna using high-order modes for millimeter-wave application," IEEE Transactions on Antennas and Propagation, vol. 63, no. 11, pp. 4624-4631, 2015.

[10] N. M. Nor, M. H. Jamaluddin, M. R. Kamarudin, and M. Khalily, "Rectangular dielectric resonator antenna array for $28 \mathrm{GHz}$ applications," Progress in Electromagnetics Research C, vol. 63, pp. 53-61, 2016.

[11] P. J. Gibson, "The Vivaldi aerial," in 9th European Microwave Conference, pp. 101-105, Brighton, UK, 1979.

[12] P. Kumar, Z. Akhter, A. K. Jha, and M. J. Akhtar, "Directivity enhancement of double slot Vivaldi antenna using anisotropic zero-index metamaterials," in 2015 IEEE International Symposium on Antennas and Propagation \& USNC/URSI National Radio Science Meeting, pp. 2061-2062, Vancouver, BC, Canada, 2015.

[13] J. Bourqui, M. Okoniewski, and E. C. Fear, "Balanced antipodal Vivaldi antenna with dielectric director for near-field microwave imaging," IEEE Transactions on Antennas and Propagation, vol. 58, no. 7, pp. 2318-2326, 2010.

[14] P. Juyal and L. Shafai, "A novel high-gain printed antenna configuration based on $\mathrm{TM}_{12}$ mode of circular disc," IEEE Transactions on Antennas and Propagation, vol. 64, no. 2, pp. 790-796, 2016.

[15] X. Zhang and L. Zhu, "High-gain circularly polarized microstrip patch antenna with loading of shorting pins," IEEE Transactions on Antennas and Propagation, vol. 64, no. 6, pp. 2172-2178, 2016.

[16] X. Zhang and L. Z, "Gain-enhanced patch antenna without enlarged size via loading of slot and shorting pins," IEEE Transactions on Antennas and Propagation, vol. 65, no. 11, pp. 5702-5709, 2017.

[17] J. Puskely and T. Mikulášek, "Compact wideband Vivaldi antenna array for microwave imaging applications," in 2013 7th European Conference on Antennas and Propagation (EuCAP), pp. 1519-1522, Gothenburg, Sweden, 2013.

[18] N. Ojaroudiparchin, M. Shen, and G. Fr, "Design of Vivaldi antenna array with end-fire beam steering function for $5 \mathrm{G}$ mobile terminals," in 2015 23rd Telecommunications Forum Telfor (TELFOR), pp. 587-590, Belgrade, Serbia, 2015.

[19] A. A. El Badawy, Y. M. Abdulmaqsoud, and F. Z. Amer, "Design of Vivaldi antenna Array with enhancement of radiation characteristics for $5 \mathrm{G}$ mobile applications," International Journal of Novel Research in Electronics and Communication, vol. 3, no. 2, pp. 74-80, 2017.

[20] J. Puskely, J. Lacik, Z. Raida, and H. Arthaber, "High-gain dielectric-loaded Vivaldi antenna for $K_{\alpha}$-band applications," IEEE Antennas and Wireless Propagation Letters, vol. 15, pp. 2004-2007, 2016.

[21] W. Nannan, F. Mu, D. Tianyao, Q. Jinghui, and A. Denisov, "Research on a novel balanced antipodal Vivaldi antenna for MMW imaging system," in 2016 International Symposium on Antennas and Propagation (ISAP), pp. 362-363, Okinawa, Japan, 2016.

[22] H. Vettikalladi, W. T. Sethi, and M. A. Alkanhal, "High gain and high efficient stacked antenna array with integrated horn for $60 \mathrm{GHz}$ communication systems," International Journal of Antennas and Propagation, vol. 2014, Article ID 418056, 8 pages, 2014.

[23] Q. WU, H. YANG, G. GAO, L. GU, and F. ZHAO, “A design of high gain Archimedean spiral antenna," DEStech Transactions on Computer Science and Engineering, vol. 3, 2017.

[24] Y.-H. Ren, J. Ding, C. J. Guo, Y. C. Song, and Y. Qu, “A wideband gain-enhanced dual-polarized printed antenna based on log-periodic parasitic directors (LPPDs)," Journal of Electromagnetic Waves and applications, vol. 30, no. 8, pp. 10211031, 2016.

[25] W. Fang, P. Fei, F. Nian, Y. Yang, and K. Feng, “A compact dielectric rod antenna array for wideband millimeter-wave applications," in 2014 44th European Microwave Conference (EuMC), Rome, Italy, 2014.

[26] K. S. Yngvesson, T. L. Korzeniowski, Y. S. Kim, E. L. Kollberg, and J. F. Johansson, "The tapered slot antenna-a new integrated element for millimeter-wave applications," IEEE Transactions on Microwave Theory and Techniques, vol. 37, no. 2, pp. 365-374, 1989.

[27] S. Al-Saif, A. Al-Omar, M. A. Ashraf, and S. Alshebeili, "A millimeter wave Vivaldi antenna with contoured platted vias for next generation wireless communication systems," in 2016 17th International Symposium on Antenna Technology and Applied Electromagnetics (ANTEM), Montreal, QC, Canada, 2016.

[28] R. O. Lee and R. N. Simons, "Effect of curvature on tapered slot antennas," in Antennas and Propagation Society International Symposium, AP-S. Digest, vol. 1, pp. 188-191, Baltimore, MD, USA, 1996.

[29] J. Shin and D. H. Schaubert, "A parameter study of striplinefed Vivaldi notch-antenna arrays," IEEE Transactions on Antennas and Propagation, vol. 47, no. 5, pp. 879-886, 1999.

[30] E. J. Wilkinson, “An N-way hybrid power divider," IRE Transactions on Microwave Theory and Techniques, vol. 8, no. 1, pp. 116-118, 1960.

[31] O. Kizilbey, S. Bozdemir, and B. S. Yarman, "2-10 GHz multisection 2-way Wilkinson power divider with enhanced port match and isolation," in 2017 IEEE 18th Wireless and Microwave Technology Conference (WAMICON), pp. 1-4, Cocoa Beach, FL, USA, 2017.

[32] S. A. Goldberger, D. J. Chung, J. Haines, and K. Chang, "Compact multi-layer Wilkinson power divider for wideband phased arrays," in Radio science meeting (joint with AP-S symposium), 2015 USNC-URSI, Vancouver, BC, Canada, 2015.

[33] S. B. Cohn, "A class of broadband three-port TEM-mode hybrids," IEEE Transactions on Microwave Theory and Techniques, vol. 16, no. 2, pp. 110-116, 1968.

[34] R. J. Mailloux, Phased Array Antenna Handbook. Vol. 2, Artech House, Boston, 2005.

[35] Computer Simulation Tool, CST MWS, Dassault Systems, USA, 2016.

[36] J. He, B. Li, L. Deng et al., "Experimental demonstration of bidirectional OFDM/OQAM-MIMO signal over a multicore Fiber system," IEEE Photonics Journal, vol. 8, no. 5, pp. 1-8, 2016.

[37] Y. Xu, X. Li, J. Yu, and G. K. Chang, "Simple and reconfigured single-sideband OFDM RoF system," Optics Express, vol. 24, no. 20, pp. 22830-22835, 2016. 


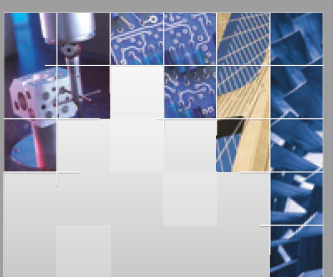

\section{Enfincering}
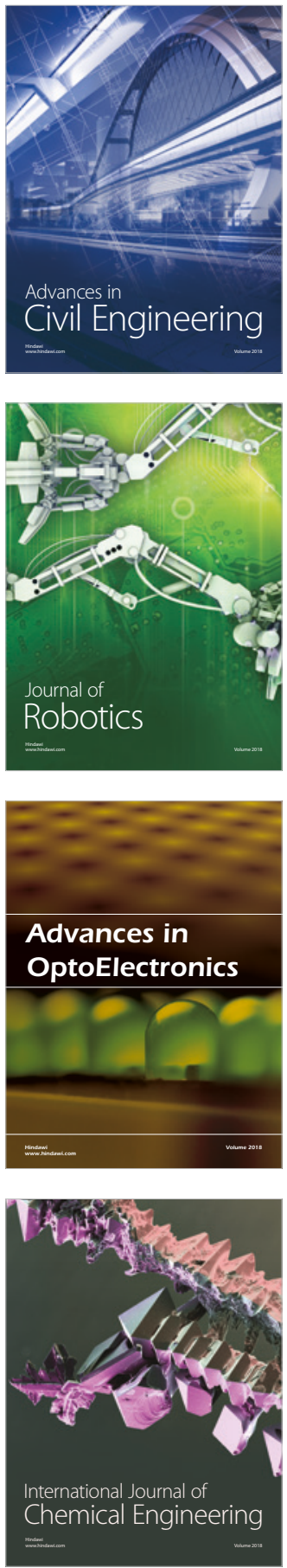

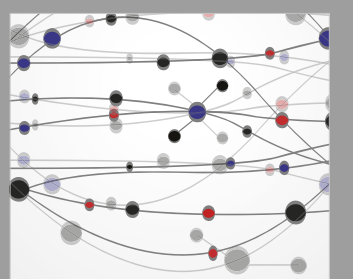

\section{Rotating \\ Machinery}

The Scientific World Journal

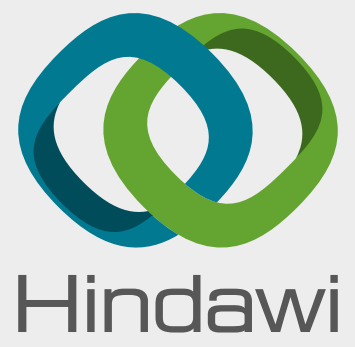

Submit your manuscripts at

www.hindawi.com
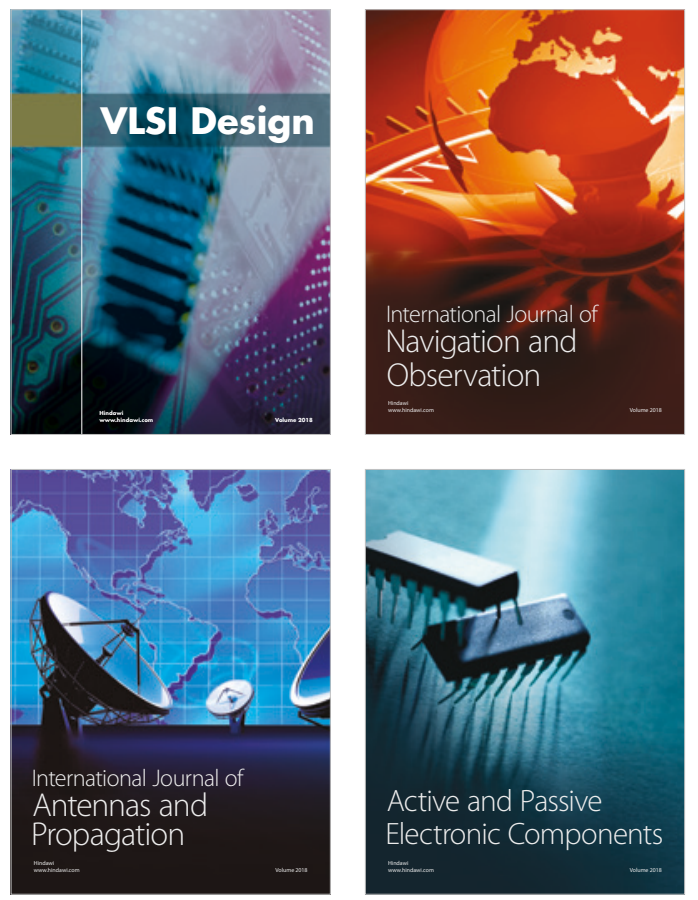
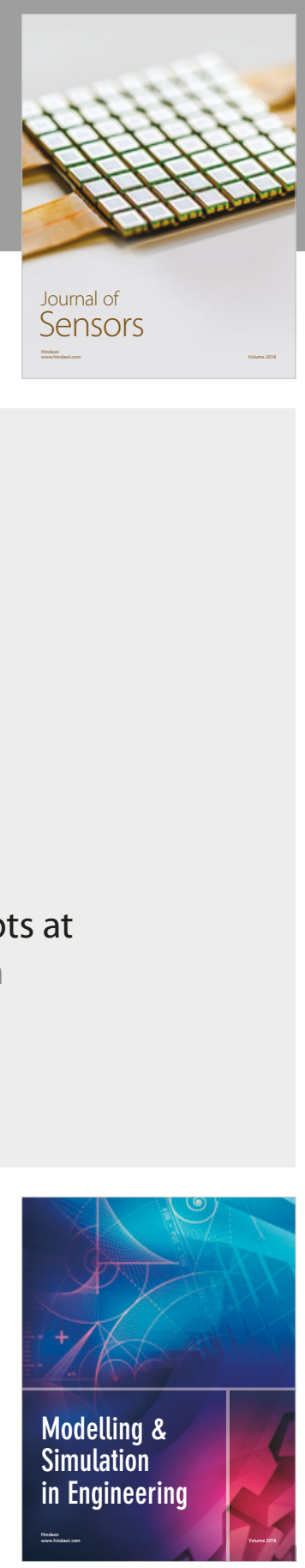

\section{Advances \\ Multimedia}
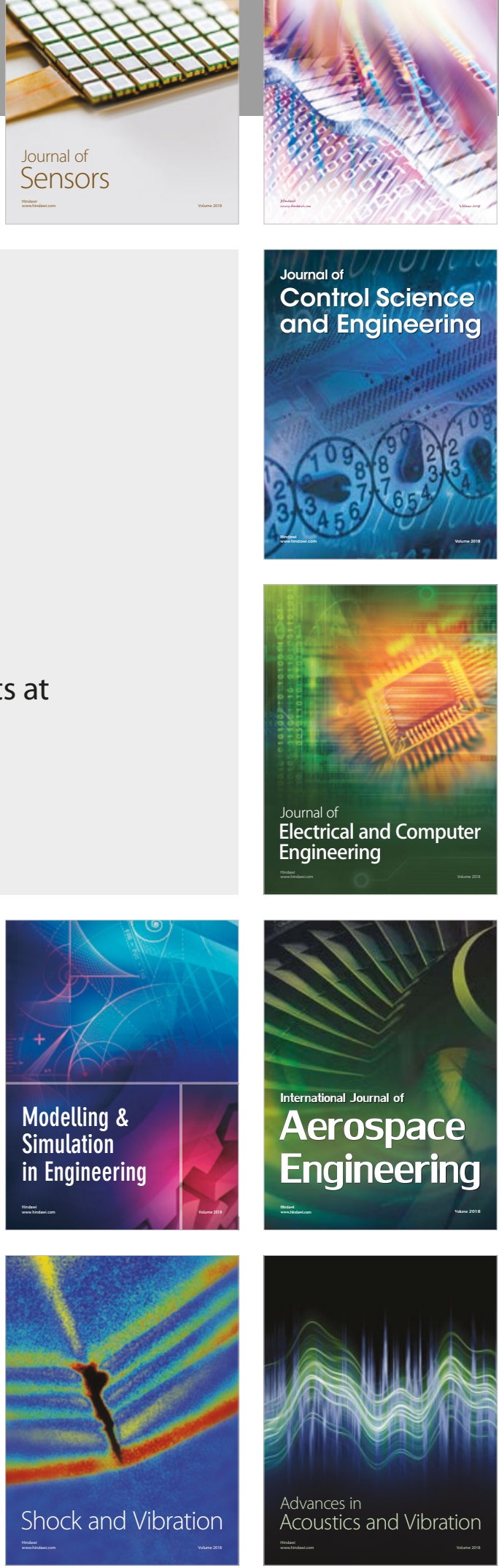